Variability of South American Convective Cloud Systems and Tropospheric Circulation during January-March 1998 and 1999

\author{
Rosana Nieto Ferreira ${ }^{* 1}$, Thomas M. Rickenbach ${ }^{2}$, Dirceu L. Herdies ${ }^{1,3}$, and Leila M. V. \\ Carvalho $^{4}$
}

${ }^{1}$ Goddard Earth Sciences and Technology Center, University of Maryland, Baltimore County (UMBC) NASA Seasonal to Interannual Prediction Project GSFC Greenbelt, MD, USA

\author{
${ }^{2}$ NASA GSFC Data Assimilation Office, Greenbelt, MD, USA. \\ (on leave from Centro de Previsão de Tempo e Estudos Climáticos, Instituto de \\ Pesquisas Espaciais, São José dos Campos, Brazil). \\ ${ }^{3}$ Joint Center for Earth Systems Technology (UMBC) \\ NASA GSFC Mesoscale Processes Branch, Greenbelt, MD, USA \\ ${ }^{4}$ Institute for Computational Earth System Sciences \\ University of California, Santa Barbara,CA, USA \\ (on leave from Departamento de Ciências Atmosféricas, Universidade de São \\ Paulo, São Paulo, Brazil).
}

Submitted to Monthly Weather Review in December 2001 *Corresponding Author Address: Rosana Nieto Ferreira, NASA GSFC, Code 913, Greenbelt, Maryland 20771 USA. Email: ferreira@janus.gstc.nasa.gov 



\title{
Variability of South American Convective Cloud Systems and Tropospheric Circulation during January-March 1998 and 1999
}

\author{
Rosana Nieto Ferreira', Thomas M. Rickenbach ${ }^{2}$, Dirceu Herdies ${ }^{3}$, Leila M. Vespoli de \\ Carvalho $^{4}$ \\ Submitted to Monthly Weather Review
}

The 2001 energy crisis in Brazil underscores the importance of understanding rainfall variability in South America. Brazil relies on its nearly 600 hydroelectric dams for 90 percent of its electricity supply. South America as a whole relies on hydroelectric power for about 50 percent of its electricity needs. A better understanding of the variability of precipitation in South America could lead to better seasonal prediction of precipitation and improving the management of energy production and consumption.

In this study a comparison of the variability of atmospheric winds and of the organization of cloudiness and rainfall in South America during January-March of 1998 (JFM98) and JanuaryMarch of 1999 (JFM99) is presented. Variations of precipitation in subtropical South America are strongly related to the variations of a northerly current that flows along the eastern side of the Andes Mountains bringing warm, moist tropical air from the Amazon basin to subtropical South America (parts of Southern Brazil, Uruguay, and Argentina). This warm, moist current is known as the South American low-level jet, or SALLJ. According to the National Center for Environmental Prediction, the SALLJ was nearly twice as strong during January-March (JFM) of the 1998 El Niño episode than during JFM of the 1999 La Niña episode. The difference in SALLJ strength between these two years translated into a stronger flow of moist tropical air into subtropical South America during JFM98. As a consequence of the enhanced moisture supply, twice as much rainfall fell in subtropical South America during JFM98 than during JFM99. Through a careful analysis of 3-hourly satellite images we found that larger and more numerous cloud systems were present in subtropical South America during JFM98 than during JFM99. The analysis of timeseries of winds and cloud system occurrence we determined that most of the large cloud systems observed in SSA occurred during times when the SALLJ was strong over Bolivia.

The difference between JFM98 and JFM99 SALLJ strength in Bolivia is in part explained by the winds produced by the South Atlantic Convergence zone (SACZ), which is a stationary region of enhanced cloudiness and precipitation that extends from the Amazon region southeastward into the Atlantic ocean. Periods when the SACZ is present are marked by southerly or weak northerly winds in Bolivia. The South Atlantic convergence zone was more prominent during JFM99 than during JFM98 leading to a weaker SALLJ during JFM99. The Southern Oscillation also contributed to the observed variability of the SALLJ in Bolivia.

In the tropical portions of South America nearly six times more cloud systems were observed during JFM99 than during JFM98. This was accompanied by more plentiful precipitation in the Amazon basin and in the Bolivian Altiplano during JFM99 than during JFM98. In this region, the Southern Oscillation was probably the most important contributor to the observed cloud system and precipitation differences.

IUMBC/Goddard Earth Sciences and Technology Center

${ }^{2}$ NASA/Goddard Space Flight Center

${ }^{3} \mathrm{UMBC} / \mathrm{Joint}$ Center for Earth Systems Technology

${ }^{4}$ University of California, Inst. for Computational Earth Systems Sciences 



\begin{abstract}
A comparison of the submonthly variability of atmospheric circulation and organization of convection in South America during January-March of 1998 (JFM98) and January-March of 1999 (JFM99) is presented.
\end{abstract}

According to the National Center for Environmental prediction reanalyses, the South American low-level jet (SALLJ) was nearly twice as strong during January-March (JFM) of the 1998 El Niño episode than during JFM of the 1999 La Niña episode. The difference in SALLJ strength between these two years translated into a stronger transport of moist tropical air into the subtropics during JFM98 than during JFM99. An objective analysis technique was used to identify large, long-lived convective cloud systems in infrared imagery. The stronger SALLJ resulted in larger and more numerous convective cloud systems and nearly twice as much rainfall in subtropical South America (parts of Southern Brazil, Uruguay, and Argentina) during JFM98 than during JFM99.

The difference between JFM98 and JFM99 SALLJ strength in Bolivia is in part explained by submonthly variability associated with the South Atlantic Convergence zone (SACZ). Periods when the SACZ is present are marked by southerly or weak northerly winds in Bolivia. The South Atlantic convergence zone was more prominent during JFM99 than during JFM98 leading to a weaker SALLJ during JFM99. On submonthly timescales, the majority of the large convective cloud systems observed in SSA occurred during times when the SACZ was absent and the SALLJ was strong over Bolivia. Interannual variability associated with the Southern Oscillation may also have contributed to the observed interannual variability of the SALLJ in Bolivia. 
In the tropical portions of South America nearly six times more convective cloud systems were observed during JFM99 than during JFM98. This was accompanied by more plentiful precipitation in the Amazon basin and in the Bolivian Altiplano during JFM99 than during JFM98. Interannual variability associated with the Southern Oscillation was an important contributor to the observed convective cloud system and precipitation differences in tropical South America. 


\section{Introduction}

The long, narrow, low-level northerly wind current that flows to the to the east of the Andes mountains year round is known as the South American low-level jet (SALLJ, e.g., Nogues-Paegle and Mo 1997, and Saulo et al. 2000). The SALLJ supplies the warm, moist tropical air that fuels convection and precipitation in the subtropical plains of South America (Saulo et al. 2000). The variability of precipitation in the subtropical plains of South America is therefore closely tied to the variability of the SALLJ. The SALLJ is in turn modulated by the Southern Oscillation on interannual timescales (Zhou and Lau 1999), frontal passages and the South Atlantic convergence zone (SACZ) on submonthly timescales, and boundary layer dynamics on diurnal timescale. A preliminary study of the spatial structure and diurnal variability of the SALLJ is presented in Saulo et al. (2000). This paper focuses on the submonthly variability of the SALLJ and organization of convection in South America during January-March of the 1998 El Niño and January-March of the 1999 La Niña .

The low-level circulation associated with frontal passages in South America modulates the intensity and location of the SALLJ on timescales of about a week. Along the eastern slope of the Andes, baroclinic waves produce strong intrusions of cold air into the tropics that organize synoptic scale bands of deep convection propagating equatorward along the frontal boundary (Garreaud, 2000). Ahead of the frontal system, low-level northwesterly flow extends from the tropics into midlatitudes contributing to a strong, well-defined SALLJ. In the wake of the frontal system low level southerly flow prevails and the SALLJ along the eastern slope of the Andes is weakened or absent.

The variability of the SALLJ on submonthly timescales is also modulated by the SACZ (Seluchi and Marengo 2000). The SACZ is a northwest-southeast oriented stationary region of 
enhanced convection that extends southeastward from the ITCZ convection anchored over the Amazon region into the South Atlantic Ocean. Each individual SACZ episode is composed of one or several midlatitude cold fronts that intrude into the subtropics and tropics, becoming stationary for a few days over southeastern Brazil. In fact, during the summertime cold fronts often organize convection not only in southern South America, but also in the Amazon basin and northeast Brazil (Kousky 1985). The SACZ is part of a well-known dipole pattern of submonthly variability of precipitation and circulation over South America (Casarin and Kousky 1986, Nogues-Paegle and Mo 1997, Liebmann et al. 1999, Nogues-Paegle et al. 2000). Depending on the position of the SACZ, tropical air flows into the subtropics at two preferred longitudes (Seluchi and Marengo 2000). When the SACZ is absent, the SALLJ is located along the eastern foothills of the Andes Mountains, in Bolivia, carrying the tropical moisture that fuels convection and precipitation in the Plata river basin. When the SACZ is present the SALLJ is displaced eastward, diverting the tropical moisture flux away from the Plata river basin and toward southeastern Brazil, along the stationary frontal zone (Rickenbach et al. 2002, Herdies et al 2002). In a study that encompassed eight southern summers, Sugahara et al. (1994) found that in days when the SALLJ is strong in Bolivia convection is intense in subtropical South America and weak in the SACZ region. They also found no modulation of Amazon convection by the strength of the SALLJ in Bolivia.

The Southern Oscillation ( $\mathrm{SO}$ ) is the most important coupled ocean-atmosphere phenomenon to produce interannual variability of global climate. In South America, the SO affects precipitation patterns in Ecuador, Peru, Amazon basin, Northeast Brazil, and also in Subtropical South America (or SSA, hereafter defined as southern Brazil, Uruguay, and Eastern Argentina/Paraguay). 
Among the most consistent SO related precipitation anomalies in the Americas is the tendency for decreased precipitation during July of an El Niño year through March of the following year in northern Brazil, Suriname, Guiana and French Guiana, and Venezuela (Ropelewski and Halpert 1987, Lau and Sheu 1988). Coastal areas of Peru and Ecuador receive more rainfall than normal during warm SO years and less rainfall than normal during cold SO years (Aceituno 1988). The tropical response to SST anomalies is dominated by atmospheric overturning in Hadley and Walker circulations (e.g. Trenberth et al. 1998). The SO affects tropical South American climate by producing zonal shifts of the Walker circulation in the Pacific-South American sector. During an El Niño year, for instance, warm equatorial SSTs and enhanced precipitation are found eastward of their normal position in the Pacific Ocean. Such an eastward shift of the precipitation in the Pacific Ocean produces an eastward shift of the Walker circulation with enhanced low-level equatorial westerlies in the eastern Pacific and enhanced lowlevel equatorial easterlies over South America and the Atlantic Ocean (e.g. Gill and Rasmusson 1983). Upper-level circulations are in the opposite sense. Upward motion occurs in the eastern Pacific where precipitation is increased and subsidence occurs over tropical South America and over the Atlantic ITCZ, suppressing precipitation in those regions (Zhou and Lau 2001).

In subtropical South America, the strongest positive precipitation anomalies occur during the austral spring of the year of the warm event (e.g., Grimm et al. 2000, and Pisciottano et al. 1994, Lau and Sheu 1988). Negative precipitation anomalies prevail in SSA during the austral spring of a cold event year. The SO precipitation anomalies in subtropical South America anomalies tend to weaken, and in some cases reverse, during the austral summer of the following year (Grimm et al. 2000, and Pisciottano et al. 1994). Tropical SST anomalies affect the extratropics indirectly through teleconnections. The precipitation and latent heating anomalies caused by SO tropical SST anomalies alter the forcing of large-scale Rossby waves that propagate into the extratropics (e.g. Trenberth et al. 1998). Ultimately, the extratropical response to SST 
anomalies such as the SO is less robust and predictable than the tropical response due to the chaotic nature of extratropical circulations such as transient baroclinic waves (e.g., Shukla et al. 2000).

Much of the growing season rainfall in the Plata River Basin is produced by large mesoscale precipitation systems. The precipitation produced by these systems benefits agriculture and hydroelectric power production in subtropical South America, but can also cause severe floods in major metropolitan areas. For instance, Torres and Nicolini (1999) studied a mesoscale convective system that formed near the mouth of the Plata river and produced $308 \mathrm{~mm}$ of rain and flooding in the city of Buenos Aires, Argentina. Mesoscale convective complexes ${ }^{1}$ (Maddox 1980) are a well-studied subset of mesoscale precipitation systems characterized by large size and longevity. These systems display a nearly circular cold-cloud shield in IR satellite imagery and produce copious rainfall in many, mostly continental, regions of the world including the Plata river basin (Velasco and Fritsch, 1987, and Laing and Fritsch 1997). MCCS have been studied extensively because their large circular, long-lived cloud shields are easily identified, and their impact on the ambient large-scale flow is measurable by standard synoptic radiosonde networks (Maddox, 1983). Most MCCs occur over land regions situated on the lee side of major topographic features and downstream from a low-level jet that brings a continuous supply of warm-moist tropical air to feed the convection (Maddox 1983, and Laing and Fritsch 1997). The Plata River Basin is a favorable region for the occurrence of MCCs because of its location on the lee side of the Andes Mountains and downstream of the SALLJ that supplies the MCCs with warm-moist air from the Amazon Basin.

\footnotetext{
1 The term mesoscale convective complex (MCCs) is an infrared satellite image-based definition of cloudiness that was coined by Maddox (1980) to classify the mesoscale systems that produce copious rainfall over the North American Great Plains during the growing seasons (Spring and Summer).
} 
Velasco and Fritsch (1987) used a two-year infrared (IR) images dataset to document mesoscale convective complexes (MCCs) in the Americas and Eastern Pacific Ocean. In the tropical portions of their domain they documented the presence of MCCs in the Eastern Pacific Ocean, and in Colombia and Paraguay. In subtropical South America they documented large (500000 $\mathrm{km}^{2}$ average cold cloud shield), long-lived (mean duration of 11 hours), predominantly nocturnal MCCs (maximum cold cloud shields between 2 and 6 am local time), that had a maximum frequency of occurrence during November through January (Velasco and Fritsch 1987). Velasco and Fritsch (1987) also suggested that El Niño modulates the interannual variability of MCC frequency in subtropical South America with twice as many MCCs occurring during the 1982-1983 El Niño year than during the 1981-1982 non-El Niño year.

However, by focusing exclusively on MCCs it is likely that a large fraction of convective system variability will be missed. For example, Laing et al. (1999) reported that MCCs account for only 22 percent of wet season rainfall in the African Sahel while an average of about 50 percent of summertime rainfall in the U. S. Great Plains is associated with MCCs (Fritsch et al 1986). For this reason, Anderson and Arrit (1998) relaxed the most restrictive MCC criterion, that is, a nearly circular cloud shield, to include all large, long-lived convective cloud systems in the U. S. Great Plains. They found that this nearly tripled their convective system population.

In order to better understand the observed differences in South American atmospheric circulation and precipitation patterns between January-March 1998 (JFM980) and January-March 1999 (JFM99) we study the relationship between the SALLJ, the SACZ, and the organization of convection in South America on submonthly timescales during the two seasons. Due to the sparseness and intermittency of the South American radiosonde network, the structure and temporal variability of the SALLJ are not well known. The Southern summers of 1998 and 1999 
are well suited to the study of the SALLJ because of the unprecedented additional radiosonde and pilot balloon observations in Bolivia and Brazil during PACS-SONET and (Pan-American Climate Studies Sounding Network) and TRMM-LBA (NASA/Tropical Rainfall Measuring Mission and Large-scale Biosphere-Atmosphere Experiment) field campaigns. Sharply contrasting Southern Oscillation conditions prevailed during JFM98 and JFM99. While during JFM98 one of the strongest El Niño episodes in record was under way in the Pacific Ocean (Wolter and Timlin, 1998), strong La Niña conditions prevailed in the Pacific Ocean during JFM99. According to the National Center for Environmental Prediction (NCEP) reanalyses, the SALLJ was nearly twice as strong during JFM of the 1998 El Niño episode than during JFM of the 1999 La Niña episode. The difference in SALLJ strength between these two years translated into a stronger moisture inflow into the subtropical plains of South America during JFM98. This favored a greater number of larger, long-lived convective cloud systems and nearly twice as much rainfall in the subtropical plains of South America during JFM98 than during JFM99.

This paper is organized as follows. Section 2 discusses a convective system objective tracking technique that is applied to three-hourly IR satellite imagery in order to characterize the temporal and spatial distribution of convective cloud systems in South America. In section 3, the differences in convective cloud system populations over South America during JFM98 and JFM99 are studied within the context of the observed interannual variability of the atmospheric circulation given by the NCEP (National Center for Environmental Prediction) reanalyses. In section 4, PACS-SONET pilot balloon observations at Santa Cruz and Trinidad, Bolivia, are used to validate the NCEP reanalyses and to study the submonthly variability of circulation and convective cloud systems during the two years.

\section{Convective system IR tracking technique}


A half-hourly global geostationary infrared (IR) data set (14 $\mathrm{km}$ resolution) for JFM98 and JFM99 was obtained from the Global Hydrology Resource Center (GHRC) at the Global Hydrology and Climate Center. These images have been remapped by GHRC to a Mercator projection, making it possible to navigate the images with good accuracy. We extracted a subset of the global images over South America, and applied a conversion from IR count to brightness temperature used for the GOES- 8 satellite. For this study, only IR images every three hours were examined. The IR images for the periods between 1-4 and 7-9 January 1999 were missing.

Convective cloud systems were identified and tracked in consecutive IR images with the use of the Maximum Spatial Correlation Tracking Technique (MASCOTTE) (Carvalho and Jones 2001). Convective cloud systems are tracked with the assumption that the spatial correlation between regions defined by a given convective cloud system in consecutive images remains above a certain threshold. The methodology of identification of convective cloud systems and determination of the evolution and structural properties of its cloud shield using IR images is briefly discussed below. For more information on tracking techniques the reader is referred to Carvalho and Jones (2001), and Machado et al. (1998).

Individual convective cloud systems are defined as contiguous regions with brightness temperature (Tb) lower than $220^{\circ} \mathrm{K}$ in the GOES IR images. While a threshold of $235^{\circ} \mathrm{K}$ for Tb has been used to identify structural properties of convective cloud systems in previous studies of MCCs (e.g. Maddox 1980, and Velasco and Fritsch 1987), a careful examination of the IR images identified numerous problems with the use of the $235^{\circ} \mathrm{K}$ threshold. In the images used in this study, the $235^{\circ} \mathrm{K}$ contour often covered very large areas, many times an entire front or large areas of multiple convective cloud systems. The splitting, merging, and loss of continuity of the systems defined by the $235^{\circ} \mathrm{K}$ contour also caused the statistics produced by MASCOTTE using 
that threshold to be of little value. The MASCOTTE tracks were much improved with the use of the $220^{\circ} \mathrm{K}$ threshold. McAnelly and Cotton (1989) also modified Maddox's (1983) MCC identification threshold to use the $220^{\circ} \mathrm{K}$ brightness temperature contour in their study of $\mathrm{MCC}$ lifecycle and rainfall production over the U. S. Great Plains. As a justification for changing Maddox's temperature threshold they cite the fact that most rainfall is associated with colder cloud shields in addition to the problems discussed above. The choice of a threshold value is in fact quite arbitrary and not based on any physical property of convective cloud systems. Moreover, it is well recognized that defining convective cloud systems by the contiguous cloud shield may obscure important details of the mesoscale organization and evolution of the underlying precipitation (Rickenbach 1999). An example of that is the presence of multiple systems under a common cloud shield. Our focus here is only to identify the approximate location, duration, and extent of large, long-lived convective cloud systems.

In order to emphasize the modulation of convective cloud systems with longer life cycles, we consider systems with an equivalent radius $(R)$ of at least $100 \mathrm{~km}$. A given convective system lasts while its $\mathrm{Tb}$ is lower than $220^{\circ} \mathrm{K}, \mathrm{R}$ is greater than $100 \mathrm{~km}$, and while the correlation between its cloud shield in two consecutive images remains greater than 0.3 . The system calculates several properties of the convective system cloud shield such as its center of gravity, horizontal area, and eccentricity (defined as the ratio of minor axis to major axis of each convective system feature). In addition, MASCOTTE provides the horizontal area and coordinates of the center of gravity of the coldest portion of the cloud system defined using a temperature threshold $210^{\circ} \mathrm{K}$, which may be more closely related to the dynamically active portion of the system.

\section{Convective cloud systems and atmospheric circulation during JFM98 and JFM99}


In this section we present the results obtained from the objective convective system IR tracking technique and relate them to the observed precipitation and tropospheric circulation patterns during two contrasting SO seasons, that is, JFM98 and JFM99.

\subsection{Observed precipitation and atmospheric circulation}

The mean observed precipitation and winds over South America and surrounding oceans during a normal JFM are shown in Figure $1 \mathrm{c}$ and $2 \mathrm{c}$. The global monthly precipitation estimates at $2.5 \times 2^{\circ}$ horizontal resolution used here are based on gauge observations, satellite estimates, and numerical weather predictions (Xie and Arkin 1997). NCEP reanalyses are also available at $2.5 \times 2^{\circ}$ horizontal resolution. During JFM the Atlantic and Eastern Pacific Intertropical Convergence Zone (ITCZ) are weakest and located at their southernmost position just north of the Equator (Zhou and Lau 2001). In a normal year, JFM precipitation in excess of $9 \mathrm{~mm} \mathrm{day}^{-1}$ occurs throughout the Amazon basin with a maximum of 12 to $15 \mathrm{~mm} \mathrm{day}^{-1}$ at the mouth of the Amazon river. Over the SACZ, precipitation in excess of $6 \mathrm{~mm} \mathrm{day}^{-1}$ is observed. The SSA region receives over $3 \mathrm{~mm}^{-1} \mathrm{day}^{-1}$ of precipitation during a normal JFM. The mean observed summertime low-level flow over tropical South America is dominated by the circulation around the South Atlantic subtropical high (Figure 1c). Easterly winds flow from the equatorial Atlantic into the continent and become channeled southward by the Andes Mountains into the SALLJ. The observed mean summertime upper-level circulation over South America (Figure 2c) is characterized by the presence of a prominent anticyclone centered over Bolivia (also known as the Bolivian high), the 
subtropical jet, and a trough over Northeastern Brazil. Upward vertical velocities prevail over the Amazon basin, SACZ region and over the Atlantic ITCZ (Figure 2c).

Figure 1 shows the Xie-Arkin precipitation and NCEP low-level wind anomalies for JFM of the $1998 \mathrm{El}$ Niño and JFM of the 1999 La Niña. Anomalies were computed with respect to the JFM mean for all normal years. By definition, the Niño year had stronger rainfall and weaker trade-wind easterlies in the equatorial Eastern Pacific. Strong precipitation and wind anomalies also occurred in the Atlantic and South American sectors. While JFM98 (Niño year) had precipitation about 20 percent below average in the Atlantic ITCZ and Amazon basin, JFM99 (Niña year) had rainfall over 30 percent above average in the Western Amazon basin and in the Atlantic ITCZ. The Bolivian Altiplano had nearly 30 percent less rainfall than normal during JFM98. Strong differences also occurred in the SSA region where up to twice as much precipitation occurred during the Niño than during the Niña year. Both years had below average precipitation in the SACZ region during JFM. The stronger low-level trade-wind easterlies in the Amazon basin during JFM98 may have contributed to a stronger SALLJ, which in turn produced increased moisture flux into the SSA region during JFM98 than during JFM99. Zhou and Lau (2001) found a statistically significant positive correlation between the tropical Eastern Pacific sea-surface temperature and the strength of the SALLJ. They argue that the eastward shift of equatorial Pacific precipitation during an El Niño year causes a strengthening of the South Atlantic subtropical high which is in turn associated with stronger equatorial Atlantic easterlies and a stronger SALLJ.

The upper-level NCEP winds are shown in Figure 2. During JFM98 stronger than normal upper tropospheric equatorial westerlies were found in the Atlantic Ocean. Combined, the upper and lower-troposphere circulation and precipitation anomalies observed during JFM98 are consistent with an eastward displacement of the Walker circulation (Gill 1980, Gill and 
Rasmusson 1983). The stronger than normal upper-tropospheric subtropical jet that occurred during JFM98 may also have favored the formation of more large convective cloud systems and stronger precipitation in the SSA region.

\subsection{Convective system IR statistics}

A further triage of the convective cloud systems tracked by MASCOTTE was produced based of their size, duration, and eccentricity so as to isolate the largest, longest-lived 'MCC-like' systems. This triage consisted of eliminating from the statistics convective cloud systems that did not obey the following criteria: a) area covered by the $220^{\circ} \mathrm{K}$ contour greater than $2 \times 10^{5} \mathrm{~km}, \mathrm{~b}$ ) area covered by the $210^{\circ} \mathrm{K}$ contour greater than $1 \times 10^{4} \mathrm{~km}, \mathrm{c}$ ) eccentricity greater than 0.2 , and d) duration of at least 3 consecutive images (or at least 6 hours). As discussed in the Introduction, we relaxed the eccentricity criterion in the MCC definition so as to include all systems with large, long-lived cloud shields, without restricting the sample to only those systems with circular cloud shields. From the more than two thousand systems originally tracked by MASCOTTE, only 135 obeyed the above criteria.

The JFM98 and JFM99 spatial distributions of large, long-lived convective cloud systems at the time when they were largest are shown in Figure 3. Convective cloud systems were distributed among the three regions labeled in Figure as SSA, TROPICS, and SACZ. For the purposes of this study, the SACZ and SSA regions are defined as the two regions where strongest less than 90-day variance of OLR occurs in South America (Figure 3a of Liebmann et al. 1999). The SSA region was moreover constrained to remain to the south of the mean position of the axis of the SALLJ. The remainder of South America, and the Tropical Atlantic are defined as TROPICS. 
Table 1 shows the number of individual convective cloud systems, as well as their mean duration and mean maximum area categorized by year and region. Although each convective system is tracked by MASCOTTE using the $220^{\circ} \mathrm{K}$ contour, the position, eccentricity, and maximum area of the $210^{\circ} \mathrm{K}$ contour are used to characterize each of the convective cloud systems shown in Figure 3 and Table 1. Overall, there were half as many convective cloud systems in South America during JFM98 as there were in JFM99. While the majority of the South American convective cloud systems during JFM98 occurred in the SSA region, the majority of convective cloud systems in JFM99 occurred in the TROPICS region. In the SSA region, there were fifty percent more convective cloud systems during JFM98 (El Niño) than during JFM99 (La Niña). Velasco and Fritch (1987) found a similar ENSO modulation for MCCs in the SSA region, with twice as many MCCs during the 1982-1983 El Niño than during the 1981-1982 nonEl Niño year. Besides being more numerous, the JFM98 SSA region systems had mean maximum area about 40 percent larger than those during JFM99. In the TROPICS region, there were about six times more systems during JFM99 than during JFM98. The JFM99 systems in the TROPICS region had mean maximum area about 10 percent larger than those in JFM98. The number of convective cloud systems in the SACZ region in JFM99 was twice that of JFM98.

Hence, the increased precipitation in the SSA region during JFM98 (Figure 1a) is associated with the occurrence of more and larger convective cloud systems. Likewise, the increased precipitation in the land portion of the TROPICS region (Figure 1b) during JFM99 is associated with the occurrence of more and slightly larger convective cloud systems during JFM99 than during JFM98. The good agreement between the results of the MASCOTTE convective system statistics and the mean Xie-Arkin precipitation is expected since the GOES IR imagery is one of the datasets used in the Xie-Arkin estimation of precipitation. The convective 
system statistics, however, produces information on the spatial organization (location, size) and temporal distribution (time of occurrence and duration) of precipitating events that is absent in the Xie-Arkin precipitation dataset.

Only 8 of the 135 large convective cloud systems in this study occurred over the Atlantic Ocean (Figure 3). Although many frontal systems passed through the oceanic portions of the SACZ and SSA regions, only 5 of the oceanic convective cloud systems embedded in these frontal regions obeyed the necessary criteria for inclusion in this study. This is in part due to the fact that cloud shields of oceanic convective cloud systems were in general warmer and more elongated than those of convective cloud systems that occurred over land. In the Atlantic ITCZ region, only 3 convective cloud systems obeyed the criteria established for inclusion in this study.

A histogram of the time of day when all convective cloud systems of JFM98 and JFM99 reached their maximum cold cloud-shield area for each of the three study regions is shown in Figure 4. In good agreement with previous studies (e.g., Anagnostou et al. 1999), most convective cloud systems in the TROPICS and SACZ regions reached their maximum cold cloud-shield area in the late afternoon to early evening hours. In the SSA region most convective cloud systems reach their maximum cold cloud-shield area in the nighttime to early morning hours, also in good agreement with previous studies (e.g., Velasco and Fritsch 1987).

In summary, we have shown that very different convective system populations and largescale circulation and precipitation patterns occurred over most of South America during JFM98 and JFM99. Stronger rainfall in the SSA during JFM98 was associated with more numerous and larger convective cloud systems during that year. The tropospheric circulation during JFM98 included a stronger SALLJ and a stronger upper-tropospheric subtropical westerly jet, both of which have been shown in previous studies to favor the formation of large, long-lived convective 
cloud systems (e.g. Maddox 1980, Velasco and Fritsch 1987). Increased subsidence during the Niño year (Figure 4a) caused a decreased number of convective cloud systems and decreased precipitation in the Amazon basin when compared to the Niña year.

\section{Submonthly variability of the SALLJ and convective system statistics}

Pilot balloon observations at Santa Cruz and Trinidad (Bolivia; see Figure 3 for the location of these stations) are available for some portions of the study period. Santa Cruz and Trinidad are located in the region where the SALLJ is maximum (see Figure 1c). The mean NCEP low-level jet intensity at $850 \mathrm{mb}$ was about $8 \mathrm{~ms}^{-1}$ during JFM98 and only about $4 \mathrm{~ms}^{-1}$ during JFM99 (figure 1c). The pilot balloon observations at Trinidad and Santa Cruz were not assimilated by the NCEP reanalysis and therefore provide independent verification of the NCEP products. Figures 5 and 6 show timeseries of the observed $850 \mathrm{mb}$ meridional wind at Santa Cruz and Trinidad along with the timeseries of meridional winds analyzed by the NCEP reanalysis at the model gridpoint that is closest to Santa Cruz. Since the Santa Cruz pilot balloon dataset for JFM99 is very incomplete, we use the dataset collected at the nearby station of Trinidad during JFM 1999. While overall it can be said that the NCEP reanalysis captures well the meridional variability of the low-level wind, it is important to point out some discrepancies. The NCEP reanalysis seems to have overestimated the northerlies during the second half of February 1998 and underestimated the strength of the southerly winds associated with the SACZ episode in midFebruary, resulting in what may be an unrealistically strong analyzed mean northerly jet in Bolivia during February of 1998.

The Brazilian Space Agency's monthly climate bulletin, Climanálise, provides information on the passage of fronts in South America as well as on the status of the SACZ. Thin solid lines at the bottom of Figures $5 \mathrm{a}$ and $6 \mathrm{a}$ denote times when a frontal system was present 
anywhere along the Atlantic coast of South America. The low-level meridional wind signature of a frontal passage is marked by periods of northerly winds followed by southerly winds. Good examples are the frontal systems that occurred on January 7-11 1998 and February 10-15 1998. The latter became stationary over the coast of Rio de Janeiro between February 12-16 constituting the first SACZ episode of 1998. The boxes at the bottom of Figure 5a mark the presence of the SACZ. The SACZ episode of February of 1998 was associated with very strong low-level southerly winds in Santa Cruz that lasted for a few days and reached $30 \mathrm{~ms}^{-1}$. On average, the three SACZ periods that occurred during JFM 1998 and JFM 1999 were periods of suppressed northerly flow in Bolivia. Note that not all fronts penetrate deep enough into lower latitudes to affect stations in Bolivia. It is interesting to point out that while the February 1998 SACZ episode was produced by one frontal system, the SACZ episodes that occurred during January and February of 1999 were each produced by two or more fronts that became stationary somewhere in the southeastern coast of Brazil.

An analysis of the submonthly variability of the SALLJ and SACZ and their relationship to the presence of convective cloud systems in SSA is now presented. The histograms in Figures $5 \mathrm{~b}$ and $6 \mathrm{~b}$ show the number of occurrences of large convective cloud systems in the SSA and SACZ regions. The vast majority of large convective cloud systems in the SSA region occurred when there were strong low-level northerly winds in Bolivia. These strong bursts of low-level northerly winds carry into the SSA the tropical moisture that fuels the large convective cloud systems that occur in that region. SACZ periods were marked by weak northerly or even southerly winds in Bolivia and no convective cloud systems in the SSA region.

In summary, Figures 5 and 6 show that in the absence of the SACZ there is a tendency for stronger low-level northerly winds in Bolivia as well as a tendency for a higher number of mesoscale systems in the Plata river basin. The interannual variability of the SALLJ and 
precipitation in the SSA region observed between JFM98 and JFM99 is in part explained in terms of the variability of the SACZ on submonthly timescales. During SACZ periods, the SALLJ tends to be displaced away from the Andes mountains effectively cutting off the tropical moisture supply for the SSA region (e.g. Nogues-Paegle and Mo, 1997, Seluchi and Marengo 2000, Herdies et al. 2002, Rickenbach et al. 2002). Therefore SACZ periods are characterized by southerly winds in Bolivia and nearly no precipitation in SSA. While the SACZ was present for more than a month during JFM99, it was present for less than a week during JFM98. The weaker presence of the SACZ over South America during JFM98 than during JFM99 also contributed to a stronger SALLJ in Bolivia and stronger precipitation in the SSA during JFM98.

\section{Conclusions}

An observational study of the January-March 1998-1999 differences in atmospheric circulation and occurrence of large, long-lived convective cloud systems in South America was presented. A unique aspect of the present study is to examine the variability of precipitation during January-March 1998-1999 in South America in conjunction with the daily variability of large convective cloud systems and atmospheric circulation patterns such as the SACZ and the SALLJ.

Strongly contrasting Southern Oscillation conditions prevailed during JFM98 and JFM99. While during JFM98 one of the strongest El Niño episodes in record was under way in the Pacific Ocean, strong La Niña conditions prevailed in the Pacific Ocean during JFM 1999.

An objective analysis technique (Carvalho and Jones 2001) was used to identify large, long-lived convective cloud systems in IR imagery. Statistics were compiled on systems whose a) 
area covered by the $220^{\circ} \mathrm{K}$ contour was greater than $2 \times 10^{5} \mathrm{~km}, \mathrm{~b}$ ) area covered by the $210^{\circ} \mathrm{K}$ contour was greater than $1 \times 10^{4} \mathrm{~km}, \mathrm{c}$ ) eccentricity was greater than 0.2 , and d) lasted for at least 3 consecutive images (or at least 6 hours). Overall, half as many convective cloud systems were observed in South America during JFM98 as there were in JFM99. Moreover, while the majority of the South American convective cloud systems during JFM98 occurred in the SSA region, the majority of convective cloud systems in JFM99 occurred in the TROPICS region.

Much of the precipitation in the subtropical regions of South America is produced by mesoscale convective cloud systems like the ones described above. In the SSA region, there were fifty percent more convective cloud systems during JFM98 (El Niño) than during JFM99 (La Niña). During JFM98 convective cloud systems in the SSA region had mean maximum area about 40 percent larger than those during JFM99. The presence of larger and more numerous convective cloud systems in the SSA region during JFM98 translated into nearly twice as much large rainfall in the SSA region during JFM98 than during JFM99.

In the TROPICS region nearly six times more convective cloud systems were observed during JFM99 than during JFM98. This was accompanied by more plentiful precipitation in the Amazon basin and in the Bolivian Altiplano during JFM99 than during JFM98. The suppressed precipitation in the TROPICS region during JFM98 was associated with enhanced subsidence associated with an eastward shift of the Pacific Walker circulation.

On submonthly timescales, the majority of the large convective cloud systems in SSA occurred during periods of strong low-level northerly winds in Bolivia. These strong bursts of low-level northerly winds carried tropical moisture southward fueling the large convective cloud systems that occurred in the SSA region. In the absence of the SACZ there was a tendency for 
stronger low-level northerly winds in Bolivia (Rickenbach et al. 2002, and Herdies et al. 2002) as well as a tendency for a higher number of convective cloud systems in subtropical South America (Sugahara et al. 1994).

According to the NCEP reanalysis, the SALLJ was nearly twice as strong during JFM of the 1998 Niño episode than during the same period of the 1999 Niña episode. The stronger SALLJ during JFM98 produced a strong inflow of moist tropical air into subtropical South America favoring the formation of larger and more numerous convective cloud systems and more plentiful precipitation in SSA during that year. The presence of a stronger than normal subtropical jet during JFM98 also favored the formation of more convective cloud systems in the SSA region during that year.

To the extent that trade winds over the Amazon basin are channeled southward by the Andes Mountains (e.g. Gandu and Geisler 1991, Seluchi and Marengo 2000), it is possible that the strengthened trade easterly winds across the Amazon basin contributed to a stronger SALLJ. The variability of the SACZ on submonthly timescales may also have contributed to the observed differences in SALLJ strength and precipitation in the SSA region during JFM98 and JFM99. While the SACZ was present during more than a month in JFM99, it was present for only a few days in JFM98. During SACZ periods, the SALLJ tends to be displaced towards western and southeastern Brazil, carrying tropical moisture away from the SSA region (e.g. Nogues-Paegle and Mo, 1997, Herdies et al. 2002, Rickenbach et al. 2002). As a result of the eastward displacement of the SALLJ, southerly winds prevail in Bolivia and very little precipitation occurs in SSA during an SACZ episode. Hence, the weaker presence of the SACZ over South America during JFM98 than during JFM99 contributed to a stronger SALLJ in Bolivia and stronger precipitation in the SSA during JFM98. Both interannual variability associated with the SO, and submonthly variability associated with the SACZ contributed to a stronger SALLJ in Bolivia, and 
to more numerous and larger convective cloud systems and enhanced precipitation in the SSA during JFM98. While on intraseasonal timescales the SACZ variability is tied to the variability of the South Pacific convergence zone through a Rossby wave-guide in the South Pacific Ocean (Nogues-Paegle and Mo 1997, Liebmann et al. 1999), the interannual variability of the SACZ remains to be assessed.

The 2001 energy crisis in Brazil underscores the importance of understanding rainfall variability in South America. Brazil relies on its nearly 600 hydroelectic dams for 90 percent of its electricity supply. South America as a whole relies on hydroelectric power for about 50 percent of its electricity needs. A better understanding of the variability of precipitation in South America could lead to a better seasonal prediction of precipitation and improve the management of energy production and consumption.

\section{Acknowledgements}

This project was funded in part by grants from the NASA Large-scale Biosphere Atmosphere (LBA) Hydrology project, from the Tropical Rainfall Measuring Mission, and from FAPESP (Proc. 98/14414-0). Geostationary satellite data was obtained from the Global Hydrology Resource Center (GHRC) at the Global Hydrology and Climate Center, Huntsville, Alabama, USA. DLH contributed to this work while in a visiting scientist position with Dr. Arlindo da Silva at NASA's Data Assimilation Office. DLH's contribution to this work is part of his $\mathrm{PhD}$ thesis dissertation at the University of São Paulo, Brazil, under the advice of Dr. Maria Assunção Faus da Silva Dias. 


\section{References}

Aceituno, P., 1988: On the functioning of the Southern Oscillation in the South American sector, I, surface climate. Mon, Wea. Rev., 116, 505-525.

Anagnostou, E. N., A. J. Negri, and R. F. Adler, 1999: A satellite infrared technique for diurnal rainfall variability studies. J. Geophys. Res., 104, D24, 31477-31488.

Anderson, C. J. and R. W. Arritt, 1998: Mesoscale convective complexes and persistent elongated convective systems over the United States during 1992 and 1993. Mon. Wea. Rev., 126, 578-599.

Carvalho, L. M. V. and C. Jones, 2001: A satellite method to identify structural properties of Mesoscale Convective Systems based on Maximum Spatial Correlation Tracking Technique (MASCOTTE). J. Appl. Meteor. 1683-1701.

Casarin, D. P., and V. E. Kousky, 1986: Precipitation Anomalies in southern Brazil and atmospheric circulation variability (Portuguese). Rev. Bras. Meteor., 1, 83-90.

Climanálise, Boletim de monitoramento e análise climática, Vols. 13,14, numbers 1,2 . Available from Centro de Previsão de Tempo e Estudos Climáticos, Rodovia Presidente Dutra, $\mathrm{km}$ 240 SPRJ, 12630-000, Cachoeira Paulista - SP, Brasil, or on the web at http://www.cptec.inpe.br/products/climanalise/capal.html. 
Fritsch, J. M., R. J. Kane, and C. R. Chelius, 1986: The contribution of mesoscale convective weather systems to the warm-season precipitation in the United States. J. Clim. Appl. Meteor., 25, 1333-1345.

Gandu, A. W., and J. E. Geisler, 1991: A primitive equations model study of the effect of topography on the summer circulation over tropical South America. J. Atmos. Sci., 48 , $1822-1836$.

Garreaud, R. D., 2000: Cold air intrusions over subtropical South America: mean structure and dynamics. Mon. Wea. Rev., 128, 2544-2559.

Gill, A. E., 1980: Some simple solutions for heat-induced tropical circulation. Quart. J. R. Met. Soc., 106, 447-462.

Gill, A. E., and E. M. Rasmusson, 1983: The 1982-83 climate anomaly in the equatorial Pacific. Nature, 306, 229-234.

Grimm, A. M., V. R. Barros, and M E. Doyle, 2000: Climate variability in southern South America associated with El Niño and La Niña events. J. Climate, 13, 35-58.

Herdies, D. L., A. Silva, M. A. F. Silva Dias, and R. Nieto Ferreira, 2001: The bi-modal pattern of the summer circulation over South America. Submitted to the J. Geophys. Res.

Kousky, V. E., 1985: Atmospheric circulation changes associated with rainfall anomalies over tropical Brazil. Mon. Wea. Rev., 113, 1951-1957. 
Laing, A. G., and J. M. Fritsch, 1997: The global population of mesoscale convective complexes. Quart. J. Roy. Meteor. Soc., 123, 389-405.

Laing, A. G, J. M. Fritsch, and A. J. Negri, 1999: Contribution of mesoscale convective complexes to rainfall in Sahelian Africa: Estimates from geostationary infrared and passive microwave data. J. Appl. Meteor., 38, 957-964.

Liebmann, B., G. N. Kiladis, J. A. Marengo, T. Ambrizzi, and J. D. Glick, 1999: Submonthly variability over South America and the South Atlantic convergence zone. J. Climate, 12, 1877-1891.

Lau, K.-M and P. J. Sheu, 1988: Annual cycle, Quasi-Biennial Oscillation, and Southern Oscillation in global precipitation. J. Geophys. Res., 93, 10975-10988.

Machado, W. B. Rossow, R. L. Guedes, and A. W. Walker, 1998: Life cycle variations of mesoscale convective systems over the Americas. Mon. Wea. Rev., 126, 1630-1654.

Maddox, R. A., 1980: Mesoscale convective complexes. Bull. Am. Meteorol. Soc., 61, 1374-1387.

Maddox, R. A., 1983: Large-scale meteorological conditions associated with midlatitude, mesoscale convective complexes. Mon. Wea. Rev., 111, 1475-1493.

McAnelly, R. L. and W. R. Cotton, 1989: The precipitation life cycle of mesoscale convective complexes over the United States. Mon. Wea. Rev., 117, 784-807. 
Nogues-Paegle, J., and K. C. Mo, 1997: Alternating wet and dry conditions over South America during summer. Mon. Wea. Rev., 125, 279-291.

Nogues-Paegle, J. N., L. A. Byerle, and K. C. Mo, 2000: Intraseasonal modulation of South American summer precipitation. Mon. Wea. Rev., 128, 837-850.

Pisciottano, G., A. Díaz, G. Cazes, and C. R. Mechoso, 1994: El Niño-Southern Oscillation impact on rainfall in Uruguay. J. Climate, 7, 1286-1302.

Rickenbach, T. M., 1999: Cloud-top evolution of tropical oceanic squall lines from radar reflectivity and infrared satellite data. Mon. Wea. Rev., 127, 2951-2976.

Rickenbach, T. M., R. Nieto Ferreira, J. Halverson, D. L. Herdies, and M. A. F. Silva Dias, 2001: Modulation of convection in the southwestern Amazon basin by extratropical stationary fronts. J. Geophys. Res., In Press.

Ropelewski, C. F., and M. S. Halpert, 1987: Global and regional scale precipitation patterns associated with the el Niño/Southern Oscillation. Mon. Wea. Rev., 115, 1606-1626.

Saulo, A. C., M. Nicolini, S. C. Chou, 2000: Model characterization of the South American lowlevel flow during the 1997-1998 spring-summer season. Clim. Dynamics, 16, 867-881.

Seluchi, M. E., and J. A. Marengo, 2000: Tropical-midlatitude exchange of air masses during summer and winter in South America: climatic aspects and examples of intense events. Int. J. Climatol., 20, 1167-1190. 
Shukla, J., J. Anderson, D. Baumhefner, C. Brankivik, Y. Chang, E. Kalnay, L. Marx, T. Palmer, D. Paolino, J. Ploshay, S. Schubert, D. Straus, M. Suarez, and J. Tribbia, 2000: Dynamical seasonal prediction. Bull. Amer. Meteor. Soc., 81, 2593-2606.

Sugahara, S., R. P. Rocha, and M. L. Rodrigues, 1994: Condições atmosféricas de grande escala associadas a jato de baixos níveis na América do Sul. Proceedings of the 8th Brazilian Meteorology Conference, Brazilian Meteorological Society, 573-577.

Trenberth, K. E., G. W. Branstator, D. Karoly, A. Kumar, N.-C. Lau, and C. Ropelewski, 1998: Progress during TOGA in understanding and modeling global teleconnections associated with tropical sea surface temperatures. J. Geophys. Res., 103, 14291-14324.

Torres, J. C., and M. Nicolini, 1999: Analysis of a mesoscale convective system centred over the Río de la Plata. Aust. Met. Mag., 48, 261-272.

Velasco, I., and M. Fritsh, 1987: Mesoscale convective complexes in Americas. J. Geophys. Res., 92, 9591-9613.

Wolter K., and M. S. Timlin, 1998: Measuring the strength of ENSO - how does 1997/98 rank? Weather, 53, 315-324.

Xie, and Arkin, 1997: Global precipitation: A 17-year monthly analysis based on gauge observations, satellite, and numerical model outputs. Bull. Amer. Met. Soc., 78, 25392558. 
Zhou, J., and W.-K. Lau, 2001: Principal modes of interannual and decadal variability of summer rainfall over South America. Int. J. Climatol., 21, 1623-1644. 


\begin{tabular}{|c|c|ccc|}
\cline { 3 - 5 } \multicolumn{2}{c|}{} & TROPICS & SACZ & SSA \\
\hline \multirow{3}{*}{ JFM98 } & Number & 10 & 8 & 26 \\
& Max. Area $\left(10^{6} \mathrm{~km}^{2}\right)$ & 10.6 & 9.4 & 10.8 \\
& Mean Duration (h) & 16 & 11 & 20 \\
\hline \multirow{3}{*}{ JFM99 } & Number & 56 & 16 & 17 \\
& Max. Area $\left(10^{6} \mathrm{~km}^{2}\right)$ & 10.4 & 13 & 7.5 \\
& Mean Duration (h) & 15 & 17 & 18 \\
\hline
\end{tabular}

Table 1: Number, maximum area of the $210 \mathrm{~K}$ cloud shield, and duration of convective cloud systems tracked by MASCOTTE in JFM98 and JFM99 in the TROPICS, SACZ, and SSA regions. 


\section{Figure Captions}

Figure 1: Xie-Arkin precipitation and $850 \mathrm{mb}$ NCEP winds. a) 1998 anomalies, b) 1999 anomalies, and c) normal. All anomalies are calculated with respect to the normal composite. Normal years were 1979-1982, 1984-1986, 1988, 1990, 1991, 1993, 1994, 1996, and 1997.

Figure 2: Same as Figure 3, but for the $200 \mathrm{mb}$ NCEP winds.

Figure 3: Spatial distribution of convective cloud systems tracked by MASCOTTE during a) JFM98 and b) JFM99. Circles denote the position and size of each convective system at the time of maximum area (measured as the area defined by the $210^{\circ} \mathrm{K}$ brightness-temperature contour). The area of each circle is about a fifth of the area of the corresponding convective system.

Figure 4: Histogram of the time of day when all convective cloud systems that occurred during JFM98 and JFM99 reached their maximum cold cloud-shield area (measured as the area defined by the $210^{\circ} \mathrm{K}$ brightness-temperature contour) for each of the three study regions.

Figure 5: JFM98 submonthly variability of the low-level winds in Santa Cruz, Bolivia, as well as fronts, and SACZ episodes in south America, and convective cloud systems in the SSA and SACZ regions. A) Meridional component of the wind in Santa Cruz, Bolivia during JFM98. Asterisks linked by solid lines denote pilot balloon observations and dashed lines denote NCEP reanalysis data at the datapoint closest to Santa Cruz. Solid boxes and thin solid lines at the bottom of a) denote SACZ periods and frontal systems, respectively. B) 
histogram of the number of convective cloud systems that occurred in the SSA (dark grey) and $\mathrm{SACZ}$ regions (light grey).

Figure 6: Same as in Figure 5, but for JFM99. 
JFM Precipitation and NCEP $850 \mathrm{mb}$ winds a) 1998 Anomaly

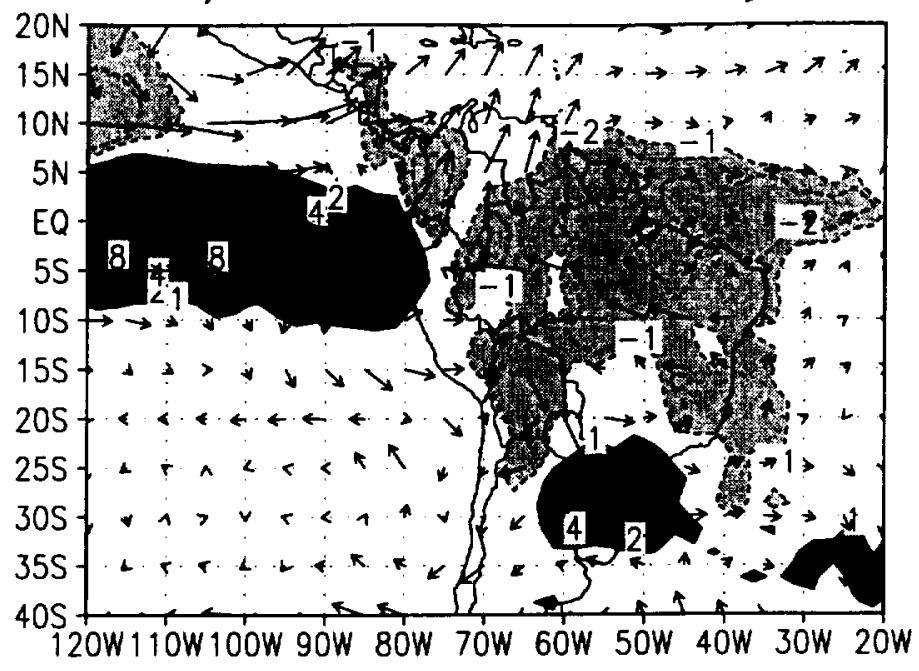

b) 1999 Anomaly



c) Normal

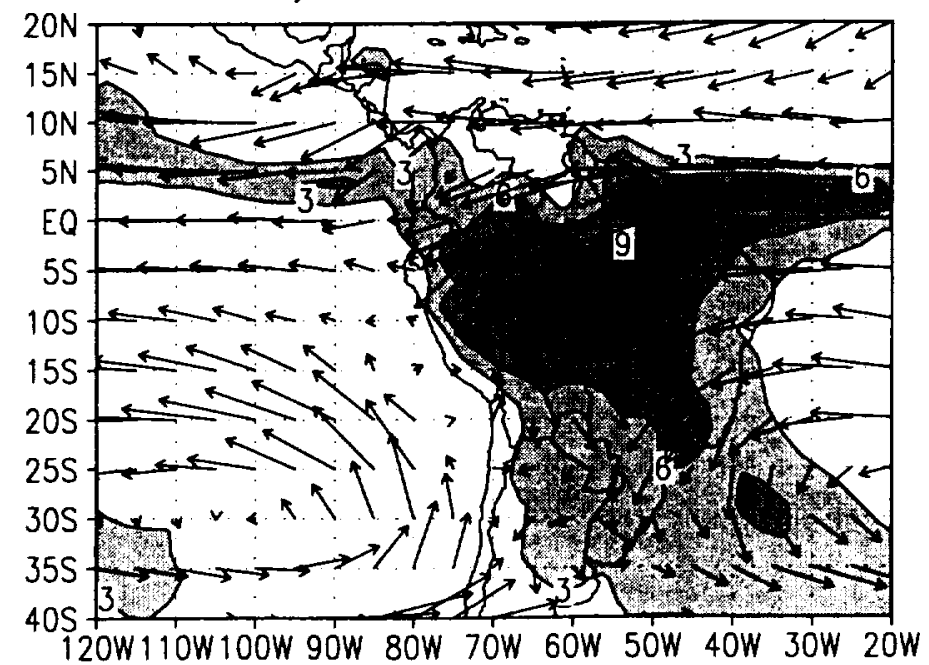



JFM NCEP $500 \mathrm{mb}$ Vertical Velocity and $200 \mathrm{mb}$ winds a) 1998 Anomaly



b) 1999 Anomaly

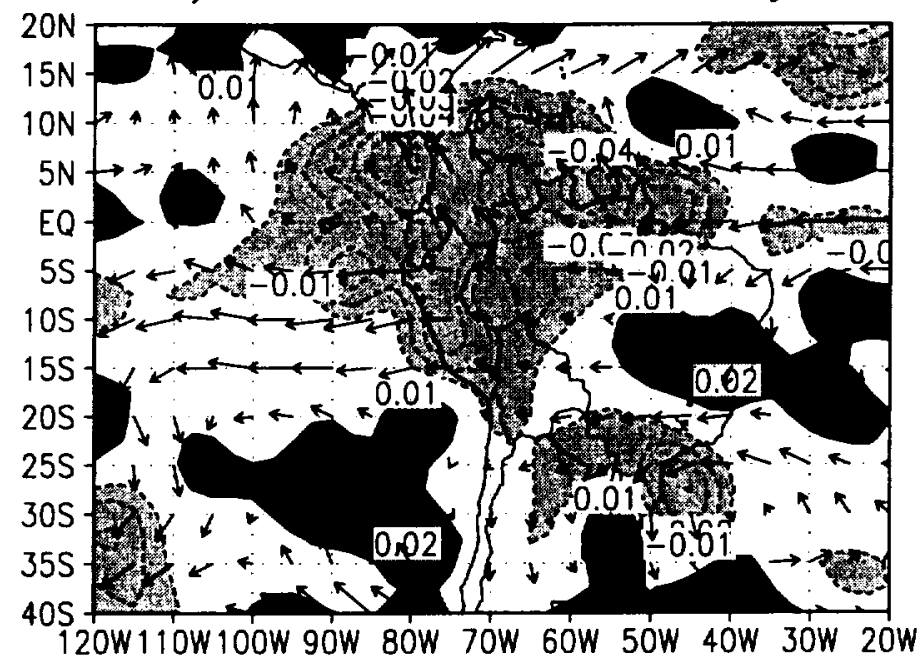

c) Normal

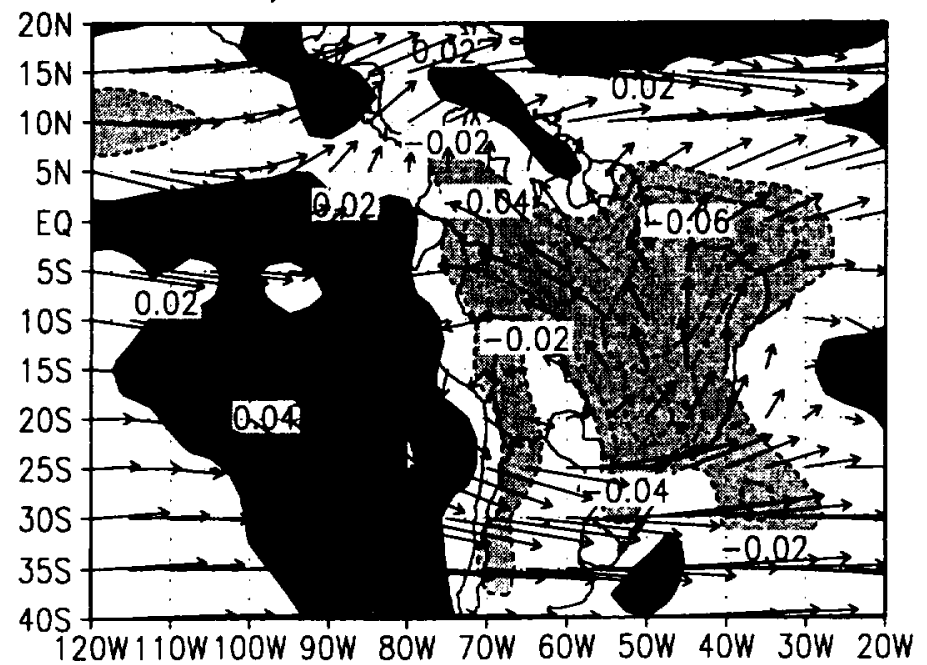


a) JFM 1998 (total $=44, \operatorname{TROPICS}=10, S A C Z=8, S S A=26)$

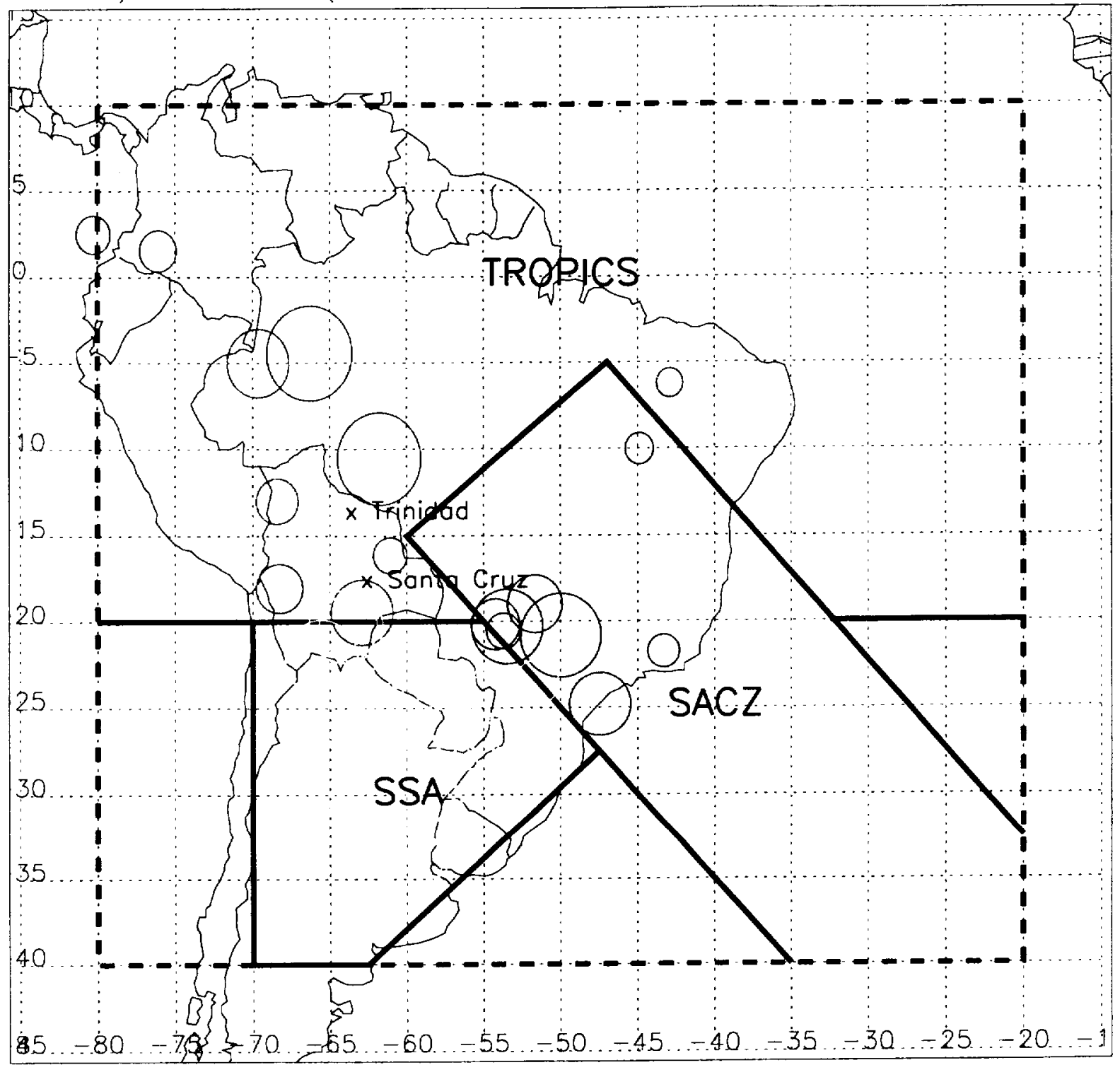



b) JFM $1999($ total=91, TROPICS $=56, S A C Z=16, S S A=17)$

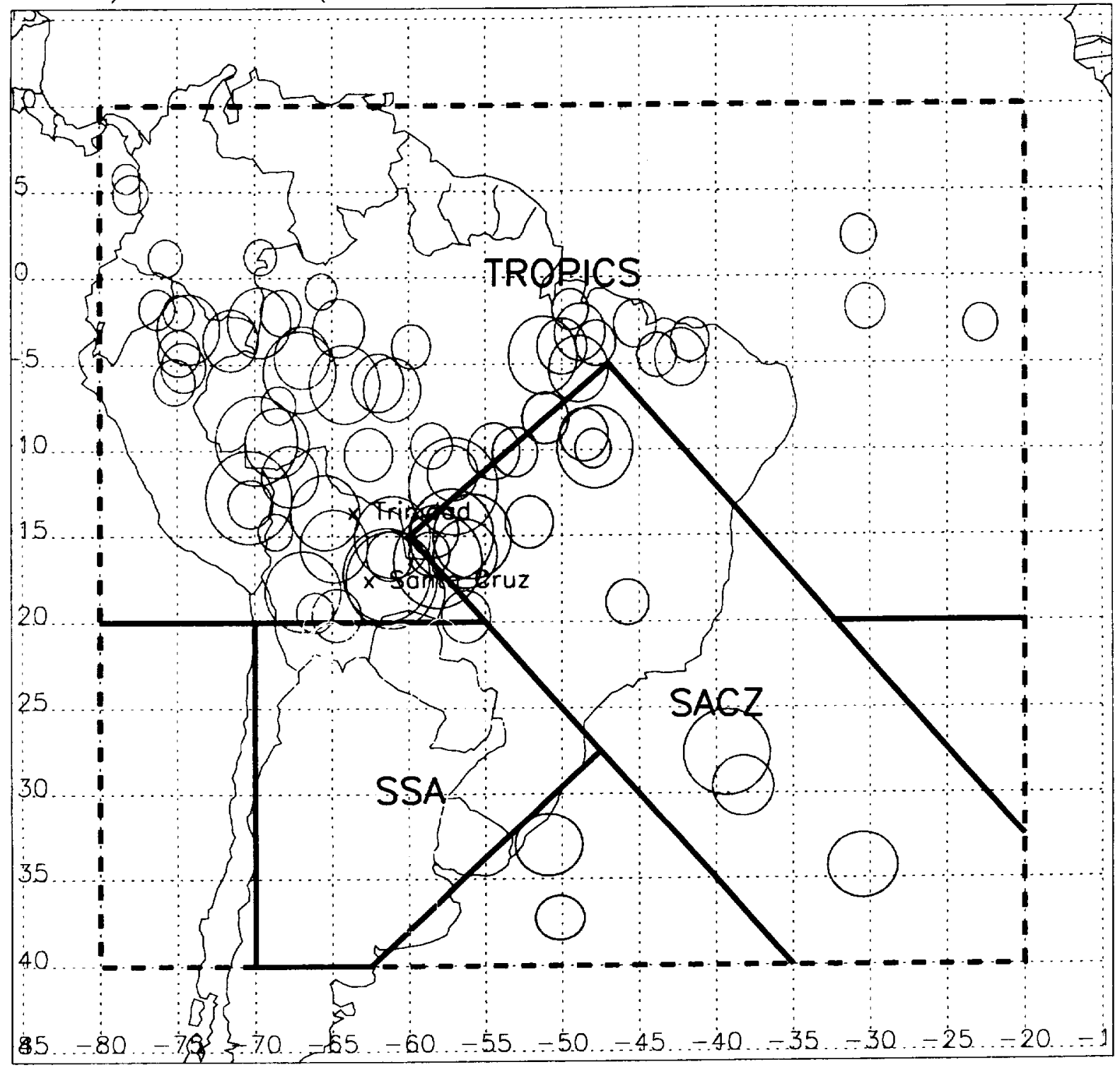

Then 
. 


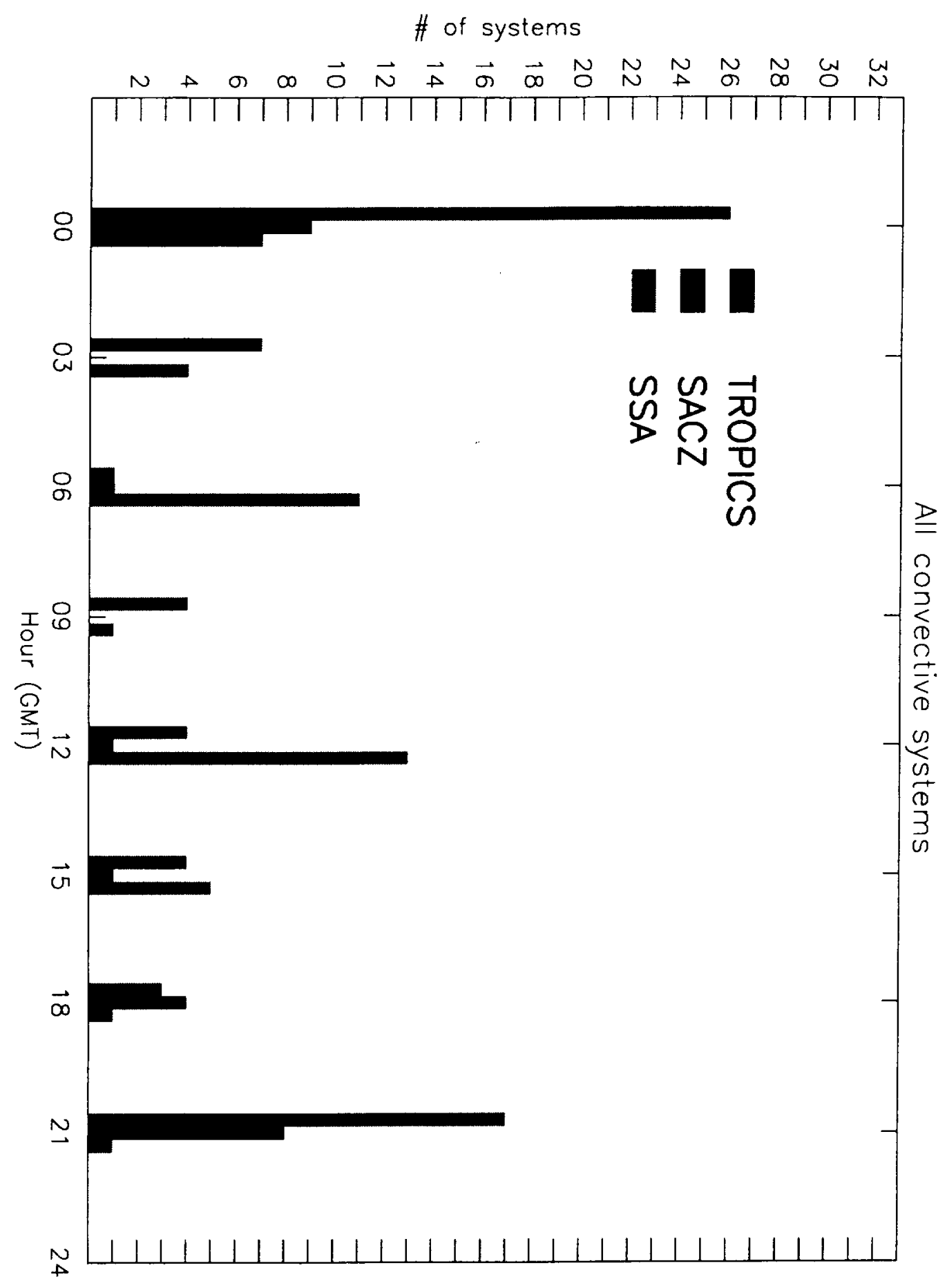

Toxin 4 

$\frac{\pi}{2}$
$\overleftarrow{\swarrow}$
$m$
$v$

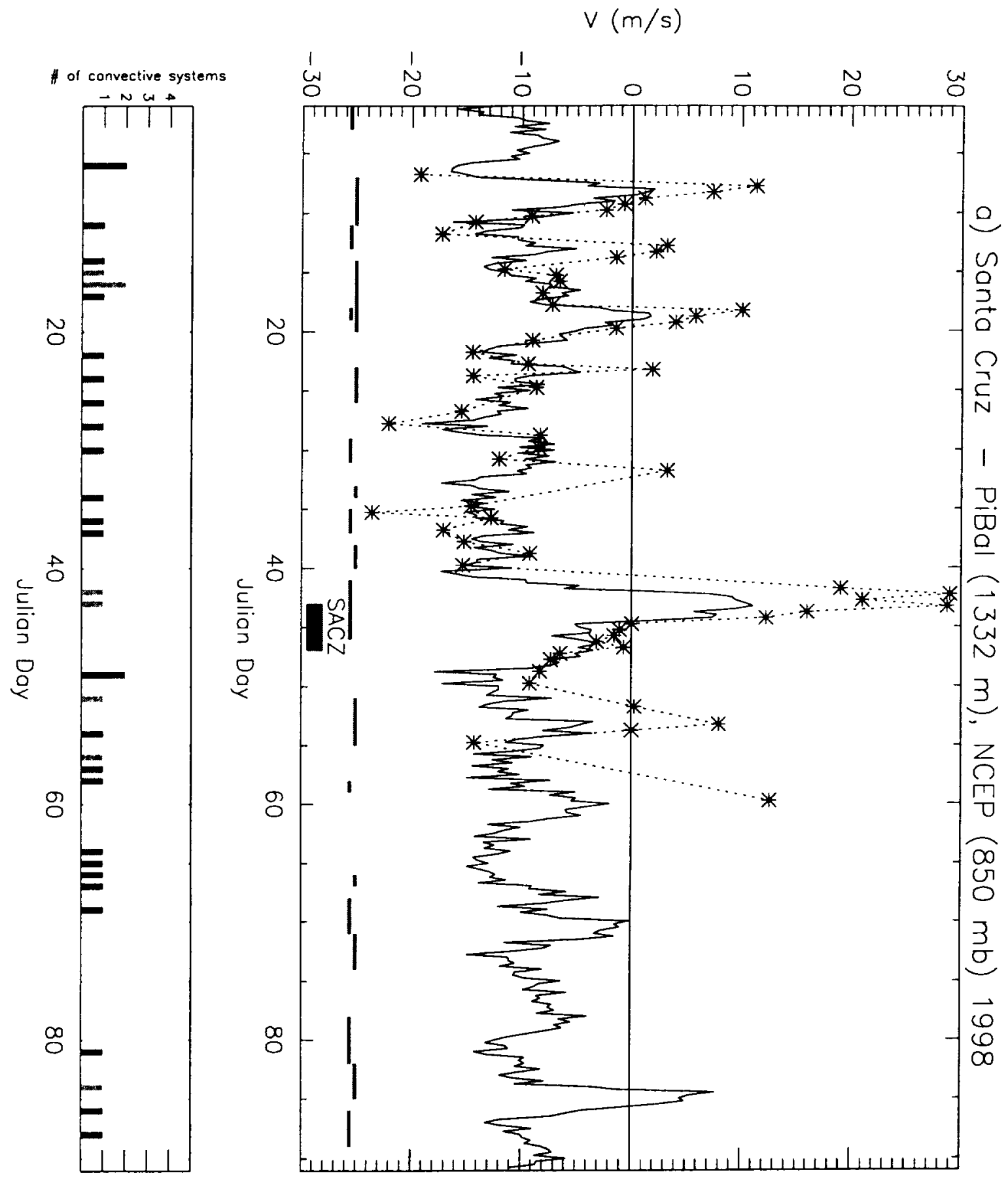



$\frac{\pi}{D}$
$\complement$
0
0
u

$$
V(m / s)
$$




